\title{
EFFECTS OF ATMOSPHERIC PLASMA TREATMENT ON ADHESION AND TRIBOLOGY OF AROMATIC THERMOPLASTIC POLYMERS
}

\author{
Hayder Al-Maliki ${ }^{1}$, László Zsidai ${ }^{1}$, Pieter Samyn ${ }^{2}$, Zoltán Szakál ${ }^{1}$, Róbert Keresztes ${ }^{1}$, \\ Gábor Kalácska ${ }^{1 *}$ \\ ${ }^{1}$ Institute for Mechanical Engineering Technology, Faculty of Mechanical Engineering, Szent István \\ University, Hungary, H-2100 Gödöllö, Páter K. u. 1. \\ ${ }^{2}$ University Hasselt, Applied and Analytical Chemistry, Institute for Materials Research (IMO- \\ IMOMEC), Agoralaan Building D, B-3590 Diepenbeek, Belgium
}

*Contact: Kalacska.Gabor@gek.szie.hu

\begin{abstract}
.
After cold plasma treatment of poly(ethylene terephthalate) and poly(ether-ether ketone) surfaces by dielectric barrier discharge (DBD) under atmospheric (air) conditions, variations in surface chemistry and morphology were investigated in relation with adhesion and tribological properties. According to XPS measurements, surface oxidation caused the formation of low molecular weight moieties of carboxylic acids. The latter resulted in more hydrophilic surfaces according to water contact angle measurements, with mainly a higher polar surface energy component. In parallel, the surface roughness of originally polished surfaces reduced due to flattening of local surface asperities after DBD. The DBD significantly improved the adhesive shear strength for different glue types in polymer/polymer and polymer/steel joints, while the best adhesion was observed for a two-component epoxy type adhesive. Under dry sliding conditions, the coefficients of friction were lower after DBD compared to pristine samples only under mild sliding conditions ( $\mathrm{v}=0.05 \mathrm{~m} / \mathrm{s} ; \mathrm{p}<1 \mathrm{MPa} . \mathrm{m} / \mathrm{s})$, while the higher normal loads caused an increase in coefficients of friction likely due to the higher contributions of surface deformation. Most interestingly, the lower coefficients of friction after DBD were observed under oil lubrication and after cleaning the sliding track ('run-out' condition), due to the better retention of oil at the sliding surface for plasma-treated polymers.
\end{abstract}

Keywords: dielectric barrier discharge, cold plasma, polymers, surface energy, adhesion, tribology 


\section{INTRODUCTION}

Due to proven corrosion resistance and lubricating ability, engineering polymers are chosen for the construction of moving parts in certain applications of micro-electronics, mechatronics or industrial equipment. In particular, the aromatic thermoplastics such as polyethylene terephthalate (PET) or polyether-etherketone (PEEK) are of interest because of high strength, stiffness and good dimensional stability; however, they often experience difficulties in gluing [1], and instability or overload during sliding [2]. Some issues can be resolved by filling solid lubricants into the polymer [3], however they also weaken the initial bulk properties. Therefore, it is worth investigating what surface modification can bring in further controlling the polymer performance simultaneously related to adhesion and sliding.

Different types of plasma treatment show potential to improve the physical and chemical surface characteristics of polymers. The changes in wettability are a fundamental parameter to control adhesion, lubrication and/or interactions with molecules. The formation of polar groups at the surface after plasma treatment, such as e.g., carbonyl, carboxyl and hydroxyl, will increase the surface energy. The enhancement of wettability after plasma treatment can be a combined effect of surface functionalization and increase in surface roughness. While surface grafting occurs relatively fast, the increase in roughness is mainly observed after longer treatment time [4]. Depending on the selection of adequate parameters, different types of plasma treatment are used for either enhancing as well as decreasing adhesion or surface hardness. The atmospheric (cold) plasma was preferred in recent years for surface modification of polymers [5], as it is a driving force to avoid expensive equipment for vacuum-based technologies and to simplify industrial applicability. Particularly for the surface modification of aromatic polymers by dielectric barrier discharge (DBD), the chemical functionalization of the polymer surface can be effectively achieved by processing at relatively low or intermediate power without introducing serious topographical damage [6]. The surface modification of a PET film by atmospheric plasma in combination with different gasses timely improved the hydrophilicity and was followed by hydrophobic recovery after longer time [7]. In parallel, significant changes in surface morphology and reactivity of PET surfaces were noticed [8,9]. While operating in air, processing parameters such as discharge power, processing speed, processing duration, and electrode configuration affect the nature and scale of the surface changes: in general, longer duration (low processing speed and a high number of cycles) and high power induce greater changes in the surface wettability of the PET [10]. Among the different studied environmental gases, air and oxygen give the highest hydrophilicity, while argon and nitrogen yield lower hydrophilicity of the PET surface [11]. In comparison to PET, the effects of DBD on PEEK were studied less frequently but it also improves hydrophilicity and adhesion [12], due to incorporation of functional groups and higher surface roughness [13]. The hydrophilicity governed by oxygenation of PEEK after DBD in air also 
recovered after several months through loss of the structurally related functional groups, but it remained more stable than other non-aromatic polymers [14].

The effects of plasma surface modification on tribological properties of polymers are not uniformly predictable, due to the multitude of governing mechanisms. It can be expected that functionalization, crosslinking, or chain scission affect chemical and mechanical surface properties that in turn will alter shear strength, friction and wear. The effect of plasma treatments on tribology was mainly studied for rubbers, indicating improvements in friction and wear resistance [15]. However, no significant changes in the coefficients of friction were reported after atmospheric plasma treatment for a series of polymers, except for polycarbonate [16]. On the other hand, the increase in crosslinking after atmospheric plasma treatment resulted in lower friction and wear of PEEK composites [17], while an argon plasma treatment resulted in higher friction of PET [18]. The effects of nitrogen plasma immersion ion implantation (PIII) for PET were investigated in previous work, indicating better scratch resistance [19]. In a following work, it was demonstrated that the benefits on sliding tribological properties strongly depend on the sliding conditions: the lower friction and wear after PIII treatment only occurred at low $p v$ conditions under dry or water-lubricated sliding and not at high $p v$ conditions [20].

In this work, the treatment of aromatic polymers including PET and PEEK by dielectric barrier discharge (DBD) will be further explored in relation with its effects on adhesion (gluing), friction and wear under dry and oil-lubricated sliding. For a better understanding of phenomena, the variations in surface chemistry and morphology will be discussed in relation with surface energies (wettability). In particular, it is of interest to determine the optimum operational sliding conditions where the plasmatreatment can provide lower coefficients of friction and wear rates compared to untreated materials.

\section{EXPERIMENTAL}

\subsection{Materials and preparation}

Two types of commercially available engineering polymers (distributed by Quattroplast Ltd., Hungary and produced by Ensinger GmbH, Germany), were used in bulk conditions (unfilled): (i) polyethylene terephthalate or PET grade DocaPET, and (ii) polyether-etherketone or PEEK grade DocaPEEK. The mechanical properties are as follows: PET (elastic modulus $\mathrm{E}=3100 \mathrm{MPa}$, tensile strength $\sigma=79$ $\mathrm{MPa}$, glass transition temperature $\mathrm{T}_{\mathrm{g}}=81^{\circ} \mathrm{C}$ ), and PEEK (elastic modulus $\mathrm{E}=4200 \mathrm{MPa}$, tensile strength $\sigma=116 \mathrm{MPa}$, glass transition temperature $\mathrm{T}_{\mathrm{g}}=150^{\circ} \mathrm{C}$ ). For adhesive tests, specimens with rectangular dimensions of $25.4 \mathrm{~mm}$ (width) x $100.0 \mathrm{~mm}$ (length) and $2.0 \mathrm{~mm}$ (thickness) were cut from extruded plates. For tribological tests, polymer specimens were machined into pins with a diameter of $10 \mathrm{~mm}$ and thickness of $4 \mathrm{~mm}$. The surfaces were subsequently polished with wet $\mathrm{SiC}$ paper (grid numbers P1200 and P400) and felt sheet towards required surface roughness (see below). 
Before testing, the samples were cleaned in an ultrasonic bath with distilled water and $96 \%$ ethanol (Reanal, Hungary). The same surface preparation was applied for samples used in adhesive tests, tribological tests, profilometry, XPS and surface energy measurements.

The counterfaces of standard steel grade S235 (Ferroglobus Ltd., Hungary) were applied for both adhesive and tribological testing. The steel surfaces were first ground and polished with $\mathrm{SiC}$ abrasive paper (grid numbers 400 and 600) with grooves oriented parallel in a single direction. The surfaces were subsequently cleaned with Loctite SF 7063 (Henkel AG \& Co., Germany) according to the supplier's technology. For tribological and adhesive tests, the average roughness of the steel plates was $\mathrm{Ra}=0.72 \pm 0.02 \mu \mathrm{m}$ perpendicular to the sliding direction and $\mathrm{Ra}=0.46 \pm 0.02 \mu \mathrm{m}$ parallel to the sliding direction (measured with SurfTest SJ-201, Mitutoyo, Japan).

\subsection{Plasma treatment}

The polymer surfaces were modified by cold atmospheric plasma treatment using a dielectric barrier discharge (DBD) equipment operating under controlled air atmosphere (temperature $20^{\circ} \mathrm{C}$, relative humidity 50\%), as shown in Figure 1a. The plasma reactor has two electrodes of circular parallel aluminum plates $(9.5 \mathrm{~cm}$ diameter, $0.5 \mathrm{~mm}$ thick) with a gap distance of $2.5 \mathrm{~mm}$, which are supplementary covered by glass discs of $2 \mathrm{~mm}$ thick and $12 \mathrm{~mm}$ diameter. The upper electrode was grounded and the lower one was employed as high-voltage electrode. The polymer samples were positioned on a horizontally moving specimen holder and introduced in the center of the reactor at a height of $1 \mathrm{~mm}$ from the electrodes to ensure homogeneous treatment over the entire surface. A sinusoidal voltage was applied through a Minipuls 4 generator (GBS Elektronik GmbH, Dresden, Germany), operating at frequencies of 5 to $20 \mathrm{kHz}$ and maximum peak values of $20 \mathrm{kV}$. The AC voltage was measured by a 1000:1 high-voltage probe (Tektronix P6015A, 75 MHz) and monitored on a digital oscilloscope (Tektronix TDS 2024B, $200 \mathrm{MHz}$ ). After preliminary testing the operational stability, the plasma reactor was run under fixed conditions of $17 \mathrm{kHz}$ frequency and $18 \mathrm{kV}$ (peak-topeak) amplitude during a treatment time of 1 minute for each sample.

The samples were stored in aluminum foil until further use. The following surface characterization and tribological testing were all done within 24 hours after the surface plasma treatment to fully include the effects of surface modification. Preliminary results revealed that the plasma-treated surfaces start to recover towards their original state after longer time (i.e., after 2 days).

\subsection{Adhesive testing}

Lap-shear tests were done according to DIN EN 1465 on single lap joints of polymer/polymer or polymer/steel pairs (bonded area $25.4 \times 12.5 \mathrm{~mm}=317.5 \mathrm{~mm}^{2}$ ). The commercial adhesives with a controlled bond line thickness of $0.1 \mathrm{~mm}$ were applied following the manufacturer procedures (Henkel 
AG \& Co., Germany), including: (i) Loctite 406 (ethyl cyano-acrylate), (ii) Loctite 9466 (twocomponent epoxy), (iii) Loctite 330 (urethane metacrylate ester). The bonding area was maintained under a constant normal load of $5 \mathrm{~N}$ during curing. The prescribed amounts of glue are approximately $0.035 \mathrm{ml}$ of Loctite 406 and $0.1 \mathrm{ml}$ for the other structural adhesives, respectively. The test samples were glued immediately after plasma treatment and stored in aluminum foil until adhesive testing was done.

For adhesive testing, the coupons were mounted in a universal mechanical tensile bench (Zwick Roell Z100, max. $100 \mathrm{kN}$ ) and the heads were pulled at $1.3 \mathrm{~mm} / \mathrm{min}$. The adhesive bonding force was determined as the maximum load upon failure of the bond and the adhesive shear strength was calculated as the force at failure per bonded surface area.

\subsection{Tribological testing}

The tribological tests were done on a pin-on-disc configuration shown in Figure $1 \mathrm{~b}$, with the polymer pin (diameter $10 \mathrm{~mm}$, thickness $4 \mathrm{~mm}$ ) mounted in a stationary holder and loaded against a rotating steel counterface (disc diameter $100 \mathrm{~mm}$, thickness $12 \mathrm{~mm}$ ). A homogeneous and parallel contact area is assured by aligning the polymer pin with a small bearing ball at the top and fixing it with a needle to avoid rotation during sliding (see Figure 1c). The polymer pin is mechanically loaded against the steel counterface through a dead-weight loading system. The radius of the frictional track can be selected by the position of the cross guiding rail and is fixed at $40 \mathrm{~mm}$ for each experiment. The friction force is measured from the bending moment induced to the pin under sliding and recorded by strain gauges. The wear is characterized by the drop in height of the polymer specimen and is measured as the vertical displacement of the pin holder with a contactless proximitor. The temperature rise is measured by a thermocouple introduced in the polymer pin at $1 \mathrm{~mm}$ above the contact zone (i.e., the polymer bulk temperature). During testing, the friction coefficient $\mu$, the vertical displacement $(\Delta h=$ wear + deformation) and the temperature $T$ are continuously monitored. Two testing protocols were followed to study the sliding under mild conditions:

- sliding tests under " $d r y$ " conditions were performed by applying a sliding velocity $v=0.05 \mathrm{~m} / \mathrm{s}$ and stepwise increasing contact pressures $p=0.5,1$ and $2 \mathrm{MPa}$ (i.e., $p v$-conditions $0.025,0.05$ and $0.1 \mathrm{MPa} . \mathrm{m} / \mathrm{s}$ ) over a sliding distance of $60 \mathrm{~m}$ (i.e., sliding time $20 \mathrm{~min}$ ) for each load. The applied time per load level was experienced as sufficient to establish steady-state sliding conditions. The total sliding distance was $180 \mathrm{~m}$ (i.e., total sliding time of $60 \mathrm{~min}$ ).

- $\quad$ sliding tests under "run-out" lubrication conditions were performed, using commercial gearbox oil (SAE 80W90): a drop of oil (10 $\mu$ l) was added onto the steel disc through a pipette in front of the polymer contact zone during a first sliding period ( $0.5 \mathrm{~m}$ distance), followed by the automatic cleaning of the lubricant layer by wiping the sliding track on the steel surface with a sponge 
during a second sliding period (9.5 m distance), shown in Figure $1 \mathrm{~d}$. As such, $(i)$ the first period of sliding corresponds to an oil-lubricating regime, while (ii) the second period of sliding is representative for a mixed or boundary lubrication regime, although the exact thickness of the lubricating oil film has not been further assessed due to its permanent change in thickness over time. The tests were run under a sliding velocity $v=0.05 \mathrm{~m} / \mathrm{s}$, contact pressure $p=0.5 \mathrm{MPa}$, and total sliding distance $10 \mathrm{~m}$.

\subsection{Surface characterization}

The surface roughness was evaluated from non-contact profilometry, using a 3D optical profilometer Coherence Correlation Interferometry (CCI) HD type (Taylor Hobson, Leicester, England) with an ultra-high precision closed loop piezoless z-scanner having a resolution in z-direction of $0.1 \AA$. The white light illumination was produced from a Fibre lite DC-950 source and measurements were made at $50 \%$ light intensity. A surface area of $330 \times 330 \mu \mathrm{m}^{2}$ was imaged by vertical scanning interferometry, with an objective lens at magnification $50 \mathrm{x}$ and numerical aperture $(\mathrm{NA})=0.55$. The scanning arrays contained $2048 \times 2048$ pixels with a field-of-view (FOV) $=330 \mu \mathrm{m}$, corresponding to a pixel size of $0.165 \mu \mathrm{m}$. The images were processed by Talymap software (Digiserve) to calculate the 3D surface roughness parameters according to ISO 25178, including Sa (average roughness), Sz (maximum height), Sku (kurtosis) and Ssk (skewness). The roughness values were determined as average from three measurements at independent surface locations, with repeatability $\mathrm{Sa}<0.2 \AA$.

The X-ray photoelectron spectroscopy (XPS) was carried out on a XSAM 800 spectrometer (Kratos, Manchester, UK) equipped with a non-monochromatic $\mathrm{Mg} \mathrm{K \alpha} \alpha_{1,2}$ radiation source $(1253.6 \mathrm{eV})$ operating under a fixed analyzer transmission mode (chamber pressure $<10^{-7} \mathrm{~Pa}$ ). The pass energy was set at $80 \mathrm{eV}$ for survey spectra (wide scan) and at $40 \mathrm{eV}$ for high resolution (detailed) spectra. The wide scan spectra were recorded at $0.5 \mathrm{eV}$ steps in the $50 \mathrm{to} 1300 \mathrm{eV}$ energy range while the detailed spectra were recorded at $0.1 \mathrm{eV}$ steps for the respective main elements. As a reference, the $\mathrm{C} 1 \mathrm{~s}$ line for the hydrocarbon $\mathrm{C}-\mathrm{H}_{\mathrm{x}}$ component was set to a binding energy of $285.0 \mathrm{eV}$. The accuracy of binding energy determination was $\pm 0.2 \mathrm{eV}$. The data acquisition and processing was performed with the Kratos Vision 2 software, applying a Shirley type background subtraction and decomposition of the peaks by using a mixed Gaussian-Lorentzian shape of equal full-width-at-half-maximum (FWHM). The quantitative analysis of the surface composition was based on integrated peak areas calculated by the XPS MultiQuent program and is expressed in $a t .-\%$.

For surface energy values, contact angles were measured by static sessile drops under controlled environmental temperature of $23^{\circ} \mathrm{C}$, using the SEE System apparatus (Advex Instruments, Czech Republic). Double distilled water and diiodomethane or $\mathrm{CH}_{2} \mathrm{I}_{2}$ (Sigma-Aldrich, Reagent Plus 99\% grade) were used as testing liquids deposited as $2 \mu \mathrm{l}$ droplets by a Hamilton syringe. The contact 
angles were measured after stabilization of the drop shape (typically after $5 \mathrm{sec}$ ) and are reported as an average of five measurements with standard deviation. From these measurements, the total surface energy together with polar and dispersive components are calculated following the Owens-Wendt method.

\section{RESULTS AND DISCUSSION}

\subsection{Surface characterization after plasma treatment}

The changes in chemical surface composition after plasma treatment were monitored by XPS analysis of PET and PEEK surfaces. The wide-scan spectra indicated three characteristic peaks at $285.0 \mathrm{eV}$ $(\mathrm{C} 1 \mathrm{~s}), 533.2 \mathrm{eV}(\mathrm{O} 1 \mathrm{~s})$ and $400.4 \mathrm{eV}(\mathrm{N} 1 \mathrm{~s})$. The elemental composition (at.-\%) before and after plasma treatment was calculated from wide-scan XPS survey spectra (Table 1). The presence of nitrogen on the pristine samples and plasma treated samples likely results from adsorption on the surface from ambient air. After plasma treatment, the oxygen content has increased and carbon content has decreased (see ratio $\mathrm{nO} / \mathrm{nC}$ ), while some more atmospheric nitrogen may have further reacted with the activated surface. It can be calculated that the amount of oxidized carbon atoms is about $13 \%$ (PET) to $19 \%$ (PEEK), which is in agreement with previous calculations indicating that the degree of oxidation was highest for PEEK and leads to opening of the aromatic rings [21]. The slight increase in nitrogen has also been observed in case of laser surface modification and is typically ascribed to the combination with oxygen at the surface [22].

The atomic percentages (at.-\%) corresponding to the different components $(\mathrm{C} 1, \mathrm{C} 2, \mathrm{C} 3, \mathrm{C} 4)$ for the $\mathrm{C} 1 s$ carbon peak and components for the $\mathrm{O} 1 s$ oxygen peak were further analyzed from high-resolution XPS spectra, comparing theoretical calculations with values for pristine and plasma-treated PET (Figure 2a) and PEEK (Figure 2b). The XPS spectra agree with literature data for PET [23] and PEEK [24] and clearly show a different state of chemical surface composition after plasma treatment. The surface of pristine polymers is contaminated with a hydrocarbon layer that is typical for most polymers and efficiently removed after plasma treatment. In addition, the variations in chemical states of carbon and oxygen are detected after plasma treatment, which might relate to surface destruction. The $\mathrm{C} 1(285.0 \mathrm{eV})$ state of carbon [C-C, C-H] has decreased in parallel with the decrease in $\mathrm{C} 2(286.0$ $\mathrm{eV})$ state of carbon [C-O] and $\mathrm{C} 3(288.7 \mathrm{eV})$ state of carbon [C=O, O-C-O], while the $\mathrm{C} 4(289.5 \mathrm{eV})$ state of carbon $[\mathrm{O}-\mathrm{C}=\mathrm{O}]$ only appeared after plasma treatment of PEEK: the latter can typically be attributed to the formation of carboxylic acid and ester bonds by oxidation in parallel with the scission of bonds in the backbone polymer due to the energy input by plasma treatment. The increase in $\mathrm{O}-$ $\mathrm{C}=\mathrm{O}$ groups and the decrease in $\mathrm{C}=\mathrm{O}$ groups suggests a replacement of the original $\mathrm{C}=\mathrm{O}$ groups of the PEEK structure with new carboxylic acid groups at the chain ends. The components in high-resolution $\mathrm{O} 1 s$ spectra confirm the previous trends with a reduction in intensity for peaks at $531.2 \mathrm{eV}[\mathrm{C}=\mathrm{O}]$ and 
higher intensity for peaks at $533.2 \mathrm{eV}$ [C-O] due to surface degradation and creation of carboxylic acids. It confirms that the ketone groups at the surface are likely reduced to hydroxyl groups after plasma treatment in parallel with formation of carboxylic acid at the chain ends, for both PET and PEEK. As a result, the relative carbon content decreased with a parallel increase in overall oxygen content. This is in agreement with reports where a surface layer of water-soluble low molecular weight oxidized polymer material had formed after DBD treatment [25]. In parallel, the nitrogen-containing functionalities such as $\mathrm{N}-\mathrm{COO}$ or OC-N-CO can be detected in minor amount for both PEEK and PET. In conclusion, the formation of polar groups containing oxygen on the surface can contribute to a hydrophilic improvement after plasma treatment.

The changes in surface topography of pristine and plasma-treated samples are illustrated by 3D noncontact profilometry surface scans of PET (Figure 3a) and PEEK (Figure 3b). The polymer surfaces after plasma treatment are flattened due to removal of the top layer and "melting" of the surface asperities, while the original machining (polishing) grooves remain visible. The surface scans were repeated at 24 and 800 hours after plasma treatment, showing good stability in surface topography. The 3D roughness parameters before and after surface treatment are summarized in Table 2. For both PEEK and PET, the surface roughness values Sa, Sz and Sku reduced and Ssk became more negative after plasma treatment, corresponding to the melting effect of plasma source causing general decrease of the original roughness. The values remain stable for 24 and 800 hours after treatment. The surface smoothening is characteristic for the used plasma processing conditions and measurements at microlevel scale. It is known that the DBD plasma generally increases the surface roughness of polymers at nanoscale level due to etching effects after long times [4], while initial decreases in surface roughness - as we also experienced in our system - also occur after short treatment times [26].

The contact angle values of water $\left(\theta_{w}\right)$ and diiodomethane $\left(\theta_{C H 212}\right)$ together with calculated surface energies of pristine and plasma-treated samples are summarized in Table 3, including total surface free energy $\left(\gamma_{\text {tot }}\right)$ with its polar component $\left(\gamma_{\text {polar }}\right)$ and dispersive component $\left(\gamma_{\text {disp }}\right)$. The contact angles and surface energies for pristine PET and PEEK are very similar. After plasma treatment, the surface energy of both polymers increases mainly due to an increase in polar component (up to $300 \%$ ) while the dispersive component slightly increases or remains almost constant. The higher surface wettability after plasma treatment is in line with the presence of polar functional groups at the surface, as confirmed by the previous XPS data. The higher hydrophilicity of polymer surfaces after DBD plasma treatment is a common feature [27]. However, the contact angles and surface energies do not remain stable in time and start to increase (resp. decrease) again after 48 hours of treatment towards values corresponding to the original surface state. The latter are mainly due to the chemical instability of the surface modification rather than to the recovery of the surface topography. 


\subsection{Adhesive tests}

The shear strength (lap-shear tests) of pristine and plasma-treated polymer/polymer and polymer/steel joints is presented for PET (Figure 4a) and PEEK (Figure 4b). In average, the statistical deviation on the shear strength ( 5 repetitions) significantly reduces after plasma treatment, i.e. about $8 \%$ for pristine PET to $1 \%$ for plasma-treated PET; about $15 \%$ for pristine PEEK to $1 \%$ for plasma-treated PEEK. The observations of failure type for the adhesive bonds are documented in Table 4, either presenting adhesive failure on one or two surfaces (1), cohesive failure in the adhesive layer (2), or cracking in the bulk polymer (3). Overall, the tendency for adhesive-type of failure reduces after plasma treatment and changes into cohesive failure or adhesive-type failure with higher shear strength. The pure cracking of the bulk polymer corresponds to highest shear strength in case of epoxy-type adhesive on plasma-treated surfaces, irrespective of the counterface. In case of adhesive failure on dissimilar surface pairs (polymer/steel), it was observed that the glue most easily releases from the polymer surface and remains sticking on the steel surfaces.

Regardless of the adhesive type and counterface, the plasma treatment improves the adhesive bonding compared to the pristine samples. The higher surface polarity after plasma treatment highly contributes to better adhesive bonding. The adhesive strength of plasma-treated PEEK is somewhat higher than plasma-treated PET, in parallel with the slightly higher surface polarity of the PEEK. There is a trend that the surface activation was most efficient for the epoxy-type of adhesive. While the epoxy provides lowest shear strength for the pristine samples, it provides highest shear strength for the plasma-treated PET and PEEK. The urethane metacrylate ester adhesive shows lower shear strength than the cyanoacrylic one for all plasma-treated samples, although the two acrylate-type adhesives show comparable shear strength for pristine PEEK samples. Considering the surface tension of the adhesives, the epoxytype is higher $(41 \mathrm{mN} / \mathrm{m})$ than the cyano-acrylate $(33 \mathrm{mN} / \mathrm{m})$ and urethane metacrylate ester (29 $\mathrm{mN} / \mathrm{m}$ ). Based on this, not only the spreading of the adhesive on the polymer surfaces (which would theoretically be expected to be best for the lowest surface tension) is important, but the approximation between the higher surface tension of the epoxy-type adhesive with the surface energy of the polymer surfaces may be advantageous in adhesive bonding. Indeed, the initial adhesive spreading has a minor role as the normal load applied during drying increases the real wetted surface area. Moreover, it seems that the reactivity of the epoxy adhesive towards the carboxylic groups at the polymer surface after plasma treatment plays a dominating role: the polarity of the polymer surface and presence of more oxygen-rich fractions after plasma treatment may cause good interactions with the pendant hydroxyl groups of the epoxy resin to form a strong adhesive bond.

\subsection{Tribological tests}

\subsubsection{Dry sliding tests}


The on-line measurements for coefficients of friction, wear and bulk temperature during dry sliding tests on pristine and plasma-treated samples under different normal loads are shown for PET (Figure 5a) and PEEK (Figure 5b). The average values for coefficients of friction $\mu$ and vertical displacement $\Delta h$ per load are summarized in Figure 6. The coefficients of friction and wear were determined from 3 repetitions with a statistical variation of $\pm 2.5 \%$ on pristine and $\pm 1 \%$ on plasma-treated samples.

The coefficients of friction for pristine PET and PEEK show significant running-in phenomena with a peak value during the first couple of meters, which can be explained by the presence of a contaminated hydrocarbon layer on the untreated polymers. Overall, the friction for pristine PEEK is slightly higher compared to pristine PET for the same normal loads, which can be attributed to the higher mechanical strength and stiffness of PEEK, providing higher sliding resistance (the surface properties of both materials can be considered as similar based on surface energy values, but the more complex aromatic structure of PEEK compared to PET may induce higher rigidity at molecular level). The coefficients of friction do not (significantly) decrease with an increase in normal loads, which is an indication that softening mechanisms and temperature rise do not influence the sliding processes (the latter would traditionally cause decreasing friction for thermoplastics under thermally controlled sliding conditions). Therefore, it can be assumed that mechanical interactions and surface interactions are dominating effects. The plasma-treated PET and PEEK present lower fiction than pristine polymers, except for the PEEK at highest normal load. It can be observed, however, that the differences in coefficients of friction between untreated and plasma-treated polymers become smaller at high loads. The observations for lower friction after plasma-treatment are in contrast from what would be expected from the higher surface energy and adhesive strength of plasma-treated surfaces, which would both imply a higher coefficient of friction. In parallel, it has also to be considered that the lower roughness of plasma-treated polymer surfaces can either increase or decrease the coefficients of friction. According to Archard's theory of friction $F_{f}$, the friction force equals the sum of an adhesion force component $F_{a}$ and a deformation force component $F_{d}$ : under low loads, the deformation component is generally smaller than the adhesion component $\left(F_{d}<F_{a}\right)$. From present results, however, it can theoretically be assumed that the lower friction for plasma-treated polymers under low loads should be attributed to the smaller contributions of a deformation component. The reduction in surface roughness for plasma-treated polymers can confirm that the deformation component near the surface asperities of the polymer should likely be reduced. At low loads, a smaller real contact area of the plasma-treated polymer surfaces can exist through the effects of plasma treatment. At higher load levels of $1 \mathrm{MPa}$, the real contact area enlarges and the higher surface energy of plasma-treated polymers could elevate the adhesive component of friction and almost equilize the difference between the pristine and treated samples. Further increase of load level to $2 \mathrm{MPa}$ showed that the increased real contact area resulted in higher friction than it was found for pristine PEEK, and the higher surface energy started dominating the friction more importantly than for PET. In parallel with the increase in 
surface energy (polarity) after plasma-treatement, a partial surface degradation and creation of a fraction oxidized material (carboxylic acid) with lower molecular weight can provide a kind of lubricating mechanism at the polymer surface, which additionally contributes to the lower friction for plasma-treated surfaces under dry sliding conditions at low loads and is worn away under high loads.

The wear and deformation $\Delta h$ of the pristine samples gradually increases at higher loads and is lower for PEEK than for PET at all load levels - in opposite to the higher friction for PEEK than for PET confirming the higher mechanical strength and higher stiffness in combination with smaller contributions of deformation for PEEK (especially, also remark the smaller static deformation during increase of the load). An estimation of wear and deformation under each normal load was made from the slope of the graph. After the plasma treatment and sliding under highest load level, the $\Delta h$ values for PET increase - in opposite to the lower friction after plasma treatment - while they remain almost similar for PEEK - in opposite to the higher friction after plasma treatment. However, the measurements of $\Delta h$ are only an indicative measurement for a couple of events over short sliding distances, including ( $i$ ) heat expansion that counteracts the 'real' wear, and (ii) creep that cooperates with the 'real' wear. As a consequence of higher friction of plasma-treated PEEK under highest load, the thermal expansion should there be at highest and suppresses the wear at most. Thus, higher 'real' wear than indicated by measurements under highest load can also be expected for the plasma-treated PEEK, which would than relate with the measurements for PET. The higher 'real' wear for plasmatreated samples after short sliding distances could be logically explained by the formation of a degraded surface layer as mentioned before.

The bulk temperatures of the polymer samples closely follow the trends for coefficients of friction for PEEK, while opposite trends have been noticed with higher temperatures corresponding to the lower friction after plasma treatment for PET. The latter can be understood by the reduction in heat conductivity of the plasma-modified surface layer in case of PET, as quantified before [28].

\subsubsection{Lubrication run-out test}

The on-line measurements for coefficients of friction under oil-lubricated sliding and "run-out" lubrication conditions are presented for pristine and plasma-treated samples of PET (Figure 7a) and PEEK (Figure 7b). The maximum and average coefficients of friction (Figure 7c) are lower than previous tests under dry sliding at $0.5 \mathrm{MPa}$. The presence of a thin lubricating film efficiently demonstrated differences in tribological properties between untreated and treated polymer samples.

After application of an oil droplet during the first period of sliding, low coefficients of friction $(<0.05)$ with almost no differences between different samples are observed through the lubrication action of an oil film. After cleaning the sliding track, friction remains lower than under dry sliding conditions 
while different behaviour occurs between pristine and plasma-treated samples: the lubricating effect responsible for low friction of plasma-treated samples lasts for longer sliding times. The lower friction under "run-out" lubrication conditions can be attributed to the better retention of the oil in the sliding interface in case of plasma-treated surfaces: the surface energy (and mainly the surface polarity) of the plasma-treated polymer surfaces is significantly higher than the pristine surfaces and therefore favourably enhances the adsorption of the hydrophobic (polar) oil lubricant on the polymer surface and entrapment in the interface. However, more periodic fluctuations in friction occur after removal of the oil from the sliding track: the latter typically indicate friction instabilities within the mixed lubrication regime and can be attributed to dynamic changes in layer thickness of the remaining lubricant. While the coefficients of friction are lower for plasma-treated surfaces than for pristine surfaces in both cases of PET and PEEK, the coefficients of friction for PEEK remain higher than for PET in parallel with the tendencies under dry sliding conditions, where it was stated that mechanical properties (i.e., higher stiffness of PEEK) can have an influence on the coefficients of friction.

\section{CONCLUSION}

In conclusion, DBD plasma treatment of polymer surfaces may induce favourable tribological properties for precision sliding components under mild conditions, especially under oil lubrication. After the dielectric barrier discharge (DBD) treatment of PET and PEEK surfaces under optimized conditions in air atmosphere, comparable effects on surface properties, adhesion, friction and wear have been observed for both polymers:

- the XPS measurements indicate the effects of surface oxidation with formation of polar functional groups and carboxylic acid moieties.

- the 3D topographical measurements indicate a reduction in surface roughness of the originally polished polymer surfaces due to flattening of the surface asperities while the machining grooves remain present.

- the contact angle measurements show higher wettability and increase in polar surface energy.

- the adhesive shear strength of polymer/polymer and polymer/steel joints increases after plasma treatment and is highest for an epoxy-type glue system.

- the coefficients of friction under dry sliding conditions are lower than pristine samples at low $p v$ factor, while coefficients of friction may become higher under more severe sliding conditions.

- as a unique feature, the coefficients of friction under oil-lubricated conditions remained low during run-out conditions for the plasma-treated samples, as a lubricating layer was retained in the sliding interface.

\section{Acknowledgements.}

This research was supported by OTKA K113039 research found. 


\section{References.}

[1] K.N. Pandiyaraj, V. Selvarajan, R.R. Deshmukh, Changyou Gao, Adhesive properties of polypropylene (PP) and polyethylene terephthalate (PET) film surfaces treated by DC glow discharge plasma, Vacuum 83 (2008), 332-339.

[2] P. Samyn, J. Quintelier, W. Ost, P. De Baets, G. Schoukens, Sliding behaviour of pure polyester and polyester-PTFE filled bulkcomposites in overload conditions, Polym Test 24 (2005), 588603.

[3] P. Samyn, J. Van Craenenbroeck, J. Quintelier, G. Schoukens, Friction induced conformational changes on large-scale and small-scale polyester sliding surfaces", Surf Interface Anal 38 (2006), 868-872.

[4] A.V. Nastuta, G.B. Rusu, I. Topala, A.S. Chiper, G. Popa. Surface modifications of polymer induced by atmospheric DBD plasma in different configurations, J Optoelect Adv Mater 10 (2008), 2038-2042.

[5] A. Van Deynse, R. Morent, N. De Geyter, Surface modification of polymers using atmospheric pressure cold plasma technology, in: Polymer Science: Research advances, practical applications and educational aspects, A. Mendez, A. Solano, Eds. Formatex Research Center, 2016, pp. 506-516.

[6] D.J. Upadhyay, N.Y. Cui, B.J. Meenan, N.M.D. Brown, The effect of dielectric barrier discharge configuration on the surface modification of aromatic polymers, J Phys D Appl Phys 38 (2005), 922-929.

[7] K. Gotoh, Y. Kobayashi, A. Yasukawa, Y. Ishigami, Surface modification of PET films by atmospheric pressure plasma exposure with three reactive gas sources, Colloid Polym Sci 209 (2012), 1005-1014.

[8] P. Esena, C. Riccardi, S. Zanini, M. Tontini, G. Poletti, F. Orsini, Surface modification of PET film by a DBD device at atmospheric pressure, Surf Coat Technol 200 (2005), 664-667

[9] U.M. Rashed, H. Ahmed, A. Al-Halwagy, A.A. Garamoon, Surface characteristics and printing properties of PET fabric treated by atmospheric dielectric barrier discharge plasma, Eur Phys $\mathbf{J}$ Appl Phys 45 (2009), 11001

[10] C. Liu, N.M.D Brown, B.J. Meenan, Uniformity analysis of dielectric barrier discharge (DBD) processed polyethylene terephthalate (PET) surface, Appl Surf Sci 252 (2006), 2297-2310.

[11] S. Onsuratoom, R. Rujiravinit, T. Sreethawong, S. Tokura, S. Chavadej, Silver loading on DBD plasma-modified woven PET surface for antimicrobial property improvement, Plasma Chem Plasma Processing 30 (2010), 191-206.

[12] S. Zhang, F. Awaja, N. James, D.R. McKenzie, A.J. Ruys, A comparison of the strength of autohesion of plasma treated amorphous and semi-crystalline PEEK films, Polym Adv Technol 22 (2011), 2496-2502. 
[13] H. Luo, G. Xiong, K. Ren, S.R. Raman, Z. Liu, Q. Li, C. Ma, D. Li, Y. Wan, Air DBD plasma treatment on three-dimensional braided carbon fiber-reinforced PEEK composites for enhancement of in vitro bioactivity, Surf Coat Technol 242 (2014), 1-7.

[14] D.J. Upadhyay, Nai-Yi Cui, C.A. Anderson, N.M.D. Brown, Surface recovery and degradation of air dielectric barrier discharge processed poly(methyl methacrylate) and poly(ether ether ketone) films, Polym Degrad Stab 87 (2005), 33-41.

[15] D.W. Segu, NBR surface modification by Ar plasma and its tribological properties, Ind Lubr Tribol 68 (2016), 227 - 232

[16] A. Bismarck, W. Brostow, R. Chiu H.E. Lobland, K.K. Ho, Effects of surface plasma treatment on tribology of thermoplastic polymers, Polym Eng Sci 48 (2008), 1971-1976.

[17] R. Zhang, A.M. Hager, K. Friedrich, Q. Song, Q. Dong, Study on tribological behaviour of plasma-treated PEEK and its composites, Wear 181 (1995), 613-623.

[18] G. J. Leggett and B. D. Beake, Development of surface morphology, local friction and adhesion in plasma-treated poly(ethylene terephthalate) films", Polym. Prep. 39 (1998), 1228.

[19] K. Kereszturi, A. Toth, M. Mohai, I. Bertoti, Surface chemical and nanomechanical alterations in plasma immersion ion implanted PET, Surf Interface Anal 40 (2008), 664-667.

[20] G. Kalacska, L. Zsidai, K. Kereszturi, M. Mohai, A. Toth, Sliding tribological properties of untreated and PIII-treated PETP, Appl Surf Sci 255 (2009), 5847-5850.

[21] E. Gonzalez, M.D. Barankin, P. Gushl, R.F. Hicks, Ring opening of aromatic polymers by remote atmospheric-pressure plasma, IEEE Trans Plasma Sci 37 (2009), 823-831.

[22] J.F. Watts, A.J. Wilson, I. Jones, F. Salamat-Zadeh, laser surface modification of poly(etheretherketone) to enhance surface free energy, wettability and adhesion, Int $\mathbf{J}$ Adhes Adhes 62 (2015), 69-77.

[23] A. Doren, M.J. Genet, P.G. Rouxhet, Analysis of Poly(Ethylene Terephthalate) (PET) by XPS, Surf Sci Spectra 3 (1994), 337-341.

[24] P. Louette, F. Bodino, J.J. Pireaux, Poly(ether ether ketone) (PEEK) XPS Reference Core Level and Energy Loss Spectra, Surf Sci Spectra 12 (2005), 149-153.

[25] K.G. Kostov, T.M.C. Nishime, L.R.O. Hein, A. Toth, Study of polypropylene surface modification by air dielectric barrier discharge operated at two different frequencies, Surf Coat Technol 234 (2013), 60-66.

[26] B. Hergelova, T. Homola, A. Zahoranava, T. Plecenik, D. Kovacik, J. Matousek, Plasma surface modification of biocompatible polymers using atmospheric pressure dielectric barrier discharge, WDS Conference proceedings, 2012, 128-133.

[27] K.G. Kostov, Y.A.A. Hamia, R.P. Mota, A.I.R. dos Santos, P.A.P. Nascente, Treatment of polycarbonate by dielectric barrier discharge (DBD) at atmospheric pressure, J Phys Conference Series 511 (2014), 012075. 
[28] G. Kalacska, R. Keresztes, L. Foldi, S. Klebert, Z. Karoly, L. Zsidai, Thermal conductivity of plasma modified polyethylene terephthalate and polyamide-6 layers, Express Polym Lett 10 (2016), 373-380. 


\section{List of Tables.}

Table 1. Elemental composition of pristine and plasma-treated polymer surfaces determined from wide-scan XPS spectra.

Table 2. 3D surface roughness parameters of pristine and plasma-treated polymer surfaces determined from non-contact profilometry.

Table 3. Surface energy of pristine and plasma-treated polymer surfaces determined from contact angle measurements.

Table 4. Failure type of adhesive bonds in lap-shear testing.

\section{List of Figures.}

Figure 1. Test equipment, (a) DBD plasma set-up, (b) pin-on-disc tribometer, (c) sample geometry, (d) oil lubrication and "run-out" lubrication testing.

Figure 2. Analysis of elemental composition from high-resolution XPS spectra, with theoretical values (first column), pristine samples (second column), plasma-treated samples (third column) for (a) PET, (b) PEEK.

Figure 3. Non-contact profilometry of pristine and plasma-treated samples $\left(330 \times 330 \mu \mathrm{m}^{2}\right.$ surface area) for (a) PET, (b) PEEK (same scale applies to all images).

Figure 4. Adhesive testing of polymer/polymer and polymer/steel couples after application of different adhesive types for pristine samples (blue, first column) and plasma-treated samples (red, second column) for (a) PET, (b) PEEK.

Figure 5. Tribological testing under dry sliding conditions at 0.5, 1 and $2 \mathrm{MPa}$, including on-line measurements for coefficients of friction, wear and displacement Dh, temperature for (a) PET, (b) PEEK

Figure 6. Tribological testing under dry sliding conditions at 0.5, 1 and $2 \mathrm{MPa}$ : summary of tribological data with (a) average coefficients of friction, (b) wear + deformation Dh.

Figure 7. Tribological testing under lubricated sliding and run-out conditions at $0.5 \mathrm{MPa}$, with (a) coefficients of friction of PET, (b) coefficients of friction of PEEK, (c) summary of average and maximum coefficients of friction. 
Table 1. Elemental composition of pristine and plasma-treated polymer surfaces determined from wide-scan XPS spectra.

\begin{tabular}{|l|c|c|c|c|}
\hline & $\mathrm{O}($ at.-\%) & $\mathrm{C} \mathrm{(at.- \% )}$ & $\mathrm{N}$ (at.-\%) & $\mathrm{nO} / \mathrm{nC}$ \\
\hline Theoretical PET & 28.58 & 71.42 & - & 0.400 \\
\hline Untreated PET & 31.60 & 68.40 & - & 0.462 \\
\hline DBD-treated PET & 36.20 & 62.00 & 1.80 & 0.584 \\
\hline Theoretical PEEK & 13.64 & 86.36 & - & 0.158 \\
\hline Untreated PEEK & 25.30 & 73.40 & 1.30 & 0.344 \\
\hline DBD-treated PEEK & 27.20 & 70.60 & 2.20 & 0.385 \\
\hline
\end{tabular}

Table 2. 3D surface roughness parameters of pristine and plasma-treated polymer surfaces determined from non-contact profilometry.

\begin{tabular}{|l|c|c|c|c|}
\hline & Sa $(\mu \mathrm{m})$ & Sz $(\mu \mathrm{m})$ & Sku $(\mu \mathrm{m})$ & Ssk $(\mu \mathrm{m})$ \\
\hline untreated PET & $0.67 \pm 0.02$ & $7.33 \pm 0.05$ & $3.80 \pm 0.04$ & $-0.07 \pm 0.01$ \\
\hline DBD-treated PET, 24h & $0.32 \pm 0.02$ & $3.36 \pm 0.04$ & $3.49 \pm 0.04$ & $-0.27 \pm 0.02$ \\
\hline DBD-treated PET, 800h & $0.30 \pm 0.02$ & $3.21 \pm 0.02$ & $3.52 \pm 0.02$ & $-0.25 \pm 0.02$ \\
\hline$\Delta$ roughness 24h / 800h (\%) & $-52.2 /-55.2$ & $-54.2 /-56.2$ & $-8.2 /-7.4$ & $315 / 284$ \\
\hline Untreated PEEK & $0.50 \pm 0.02$ & $5.94 \pm 0.02$ & $3.81 \pm 0.03$ & $-0.33 \pm 0.02$ \\
\hline DBD-treated PEEK, 24h & $0.28 \pm 0.02$ & $2.65 \pm 0.02$ & $3.44 \pm 0.03$ & $-0.38 \pm 0.02$ \\
\hline DBD-treated PEEK, 800h & $0.29 \pm 0.02$ & $2.68 \pm 0.02$ & $3.46 \pm 0.02$ & $-0.36 \pm 0.02$ \\
\hline$\Delta$ roughness 24h / 800h (\%) & $-44.0 /-42.0$ & $-55.4 /-54.9$ & $-9.7 /-9.2$ & $15.2 / 9.1$ \\
\hline
\end{tabular}


Table 3. Surface energy of pristine and plasma-treated polymer surfaces determined from contact angle measurements.

\begin{tabular}{|c|c|c|c|c|c|}
\hline & $\theta_{\mathrm{w}}\left({ }^{\circ}\right)$ & $\theta_{\mathrm{CH} 212}\left({ }^{\circ}\right)$ & $\gamma_{\text {pol }}\left(\mathrm{mJ} / \mathrm{m}^{2}\right)$ & $\gamma_{\text {disp }}\left(\mathrm{mJ} / \mathrm{m}^{2}\right)$ & $\gamma_{\text {tot }}\left(\mathrm{mJ} / \mathrm{m}^{2}\right)$ \\
\hline untreated PET & $71 \pm 3.3$ & $32 \pm 3.1$ & 6.1 & 43.4 & 49.5 \\
\hline DBD-treated PET, 24h & $30 \pm 2.7$ & $24 \pm 0.5$ & 25.3 & 46.6 & 71.9 \\
\hline DBD-treated PET, $48 \mathrm{~h}$ & $65 \pm 3.0$ & $30 \pm 2.1$ & 8.6 & 43.2 & 51.8 \\
\hline$\Delta \gamma 24 \mathrm{~h} / 48 \mathrm{~h}(\%)$ & & & $315 / 41$ & $7.4 /-0.5$ & $45.3 / 4.6$ \\
\hline Untreated PEEK & $70 \pm 1.5$ & $30 \pm 6.4$ & 6.1 & 44.3 & 50.4 \\
\hline DBD-treated PEEK, 24h & $29 \pm 2.2$ & $29 \pm 3.1$ & 26.4 & 44.9 & 71.3 \\
\hline DBD-treated PEEK, $48 \mathrm{~h}$ & $62 \pm 3.1$ & $33 \pm 2.5$ & 10.1 & 42.9 & 53.0 \\
\hline$\Delta \gamma 24 \mathrm{~h} / 48 \mathrm{~h}(\%)$ & & & $332 / 66$ & $1.4 /-3.2$ & $41.5 /-15$ \\
\hline
\end{tabular}

Table 4. Failure type of adhesive bonds in lap-shear testing.

\begin{tabular}{|l|c|c|c|c|c|c|c|c|}
\hline & \multicolumn{2}{|c|}{ Pristine PET } & \multicolumn{2}{c|}{ plasma treated PET } & \multicolumn{2}{c|}{ Pristine PEEK } & \multicolumn{2}{c|}{ plasma treated PEEK } \\
\cline { 2 - 9 } & PET/PET & PET / steel & PET/PET & PET / steel & PEEK/PEEK & PEEK / steel & PEEK/PEEK & PEEK/ steel \\
\hline Loctite 406 & $1,2,3$ & 1,2 & 2,3 & 2,3 & 1 & 1 & 1 & 1,2 \\
\hline Loctite 9466 & 1 & 1 & 3 & 3 & 1,2 & 1 & 3 & 3 \\
\hline \begin{tabular}{l} 
Loctite 330 \\
\hline
\end{tabular} & 1 & 1,3 & 1,2 & 1 & 1 & 1 & 1,2 \\
$\begin{array}{l}\text { 1. adhesive failure on one or two surfaces } \\
\text { 2. cohesive failure in the glue layer } \\
\text { 3. cracking in the bulk polymer }\end{array}$
\end{tabular}


(a)
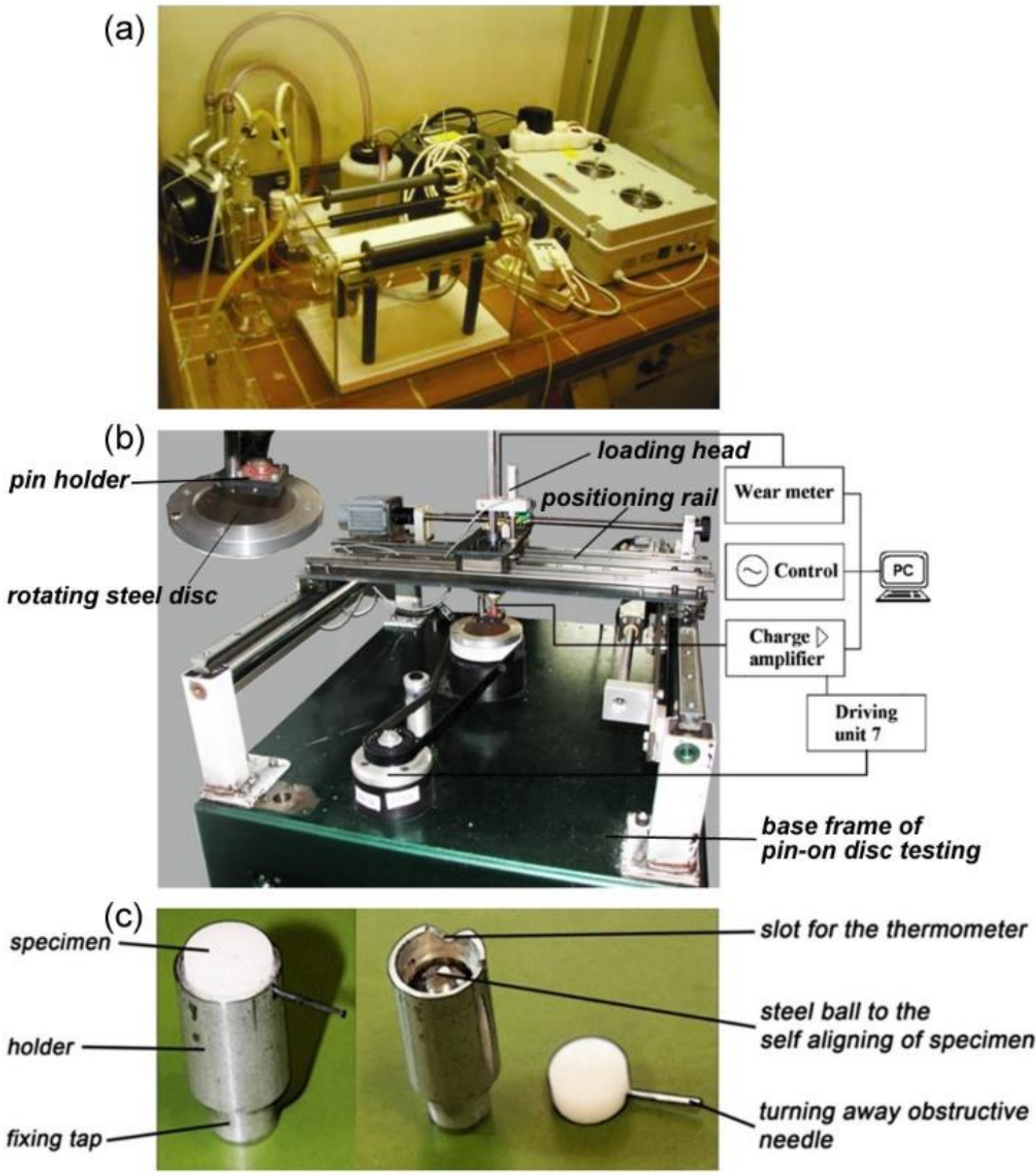

(d)

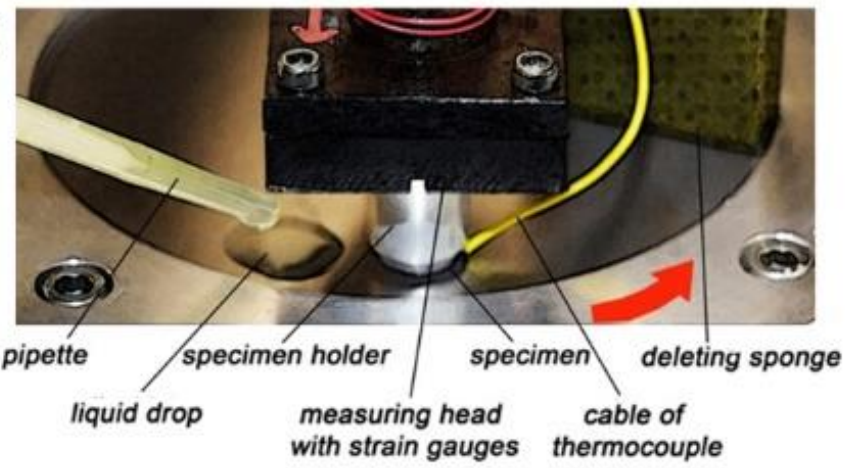

Figure 1. Test equipment, (a) DBD plasma set-up, (b) pin-on-disc tribometer, (c) sample geometry, (d) oil lubrication and "run-out" lubrication testing 
(a)

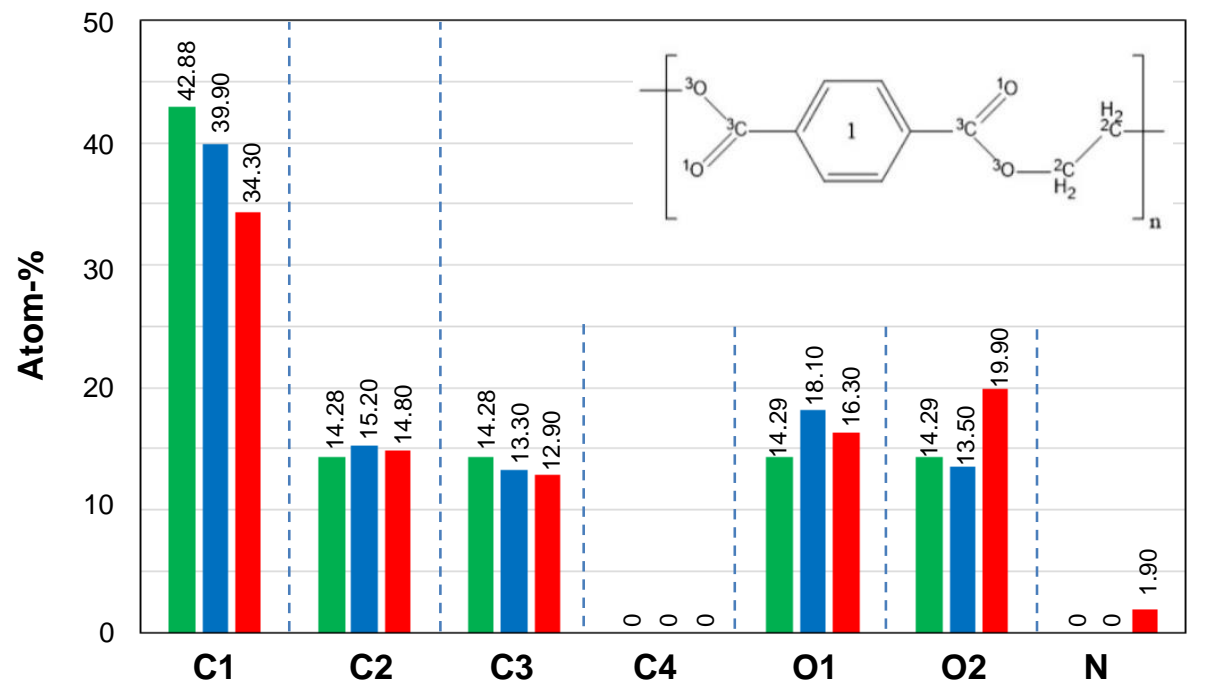

(b)

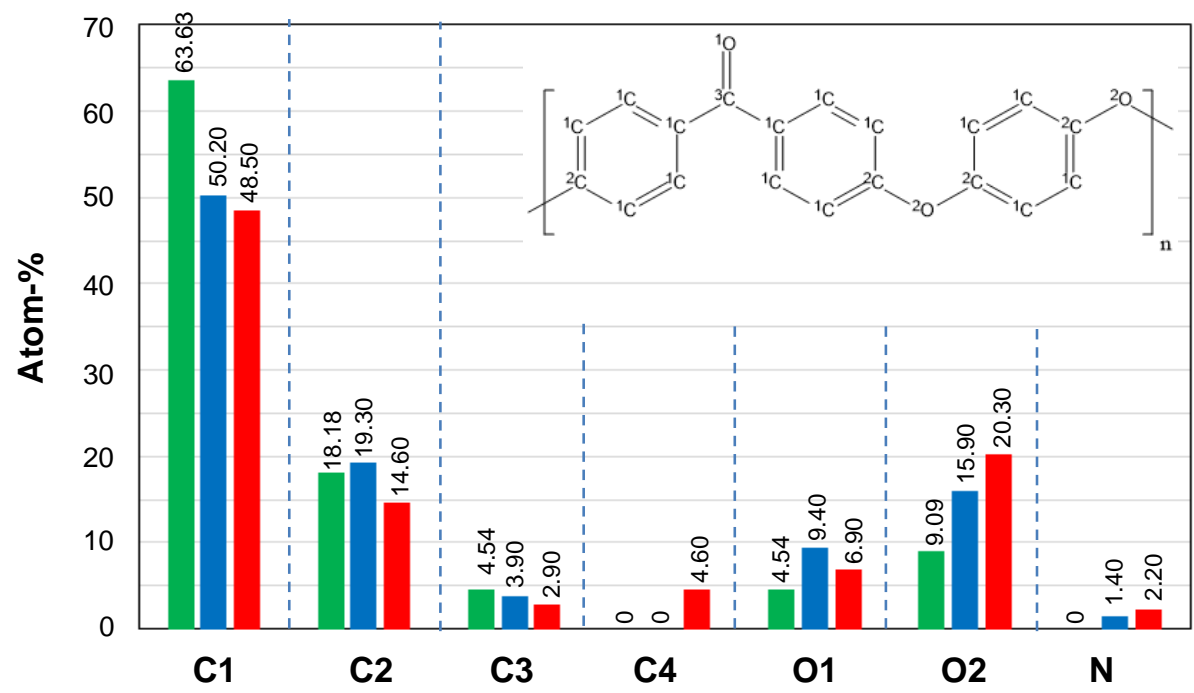

Figure 2. Analysis of elemental composition from high-resolution XPS spectra, with theoretical values (first column), pristine samples (second column), plasma-treated samples (third column) for (a) PET, (b) PEEK. 


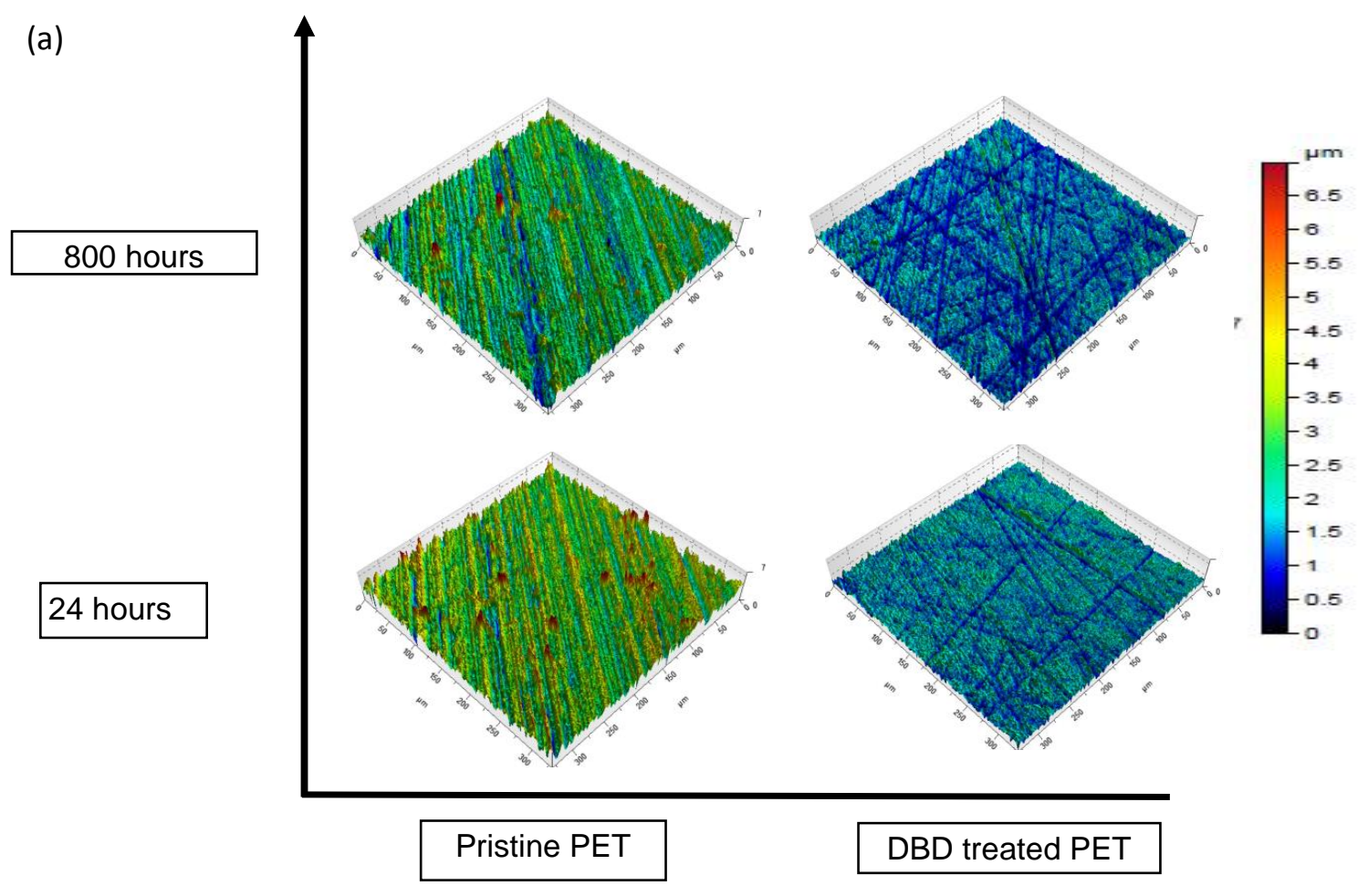

(b)

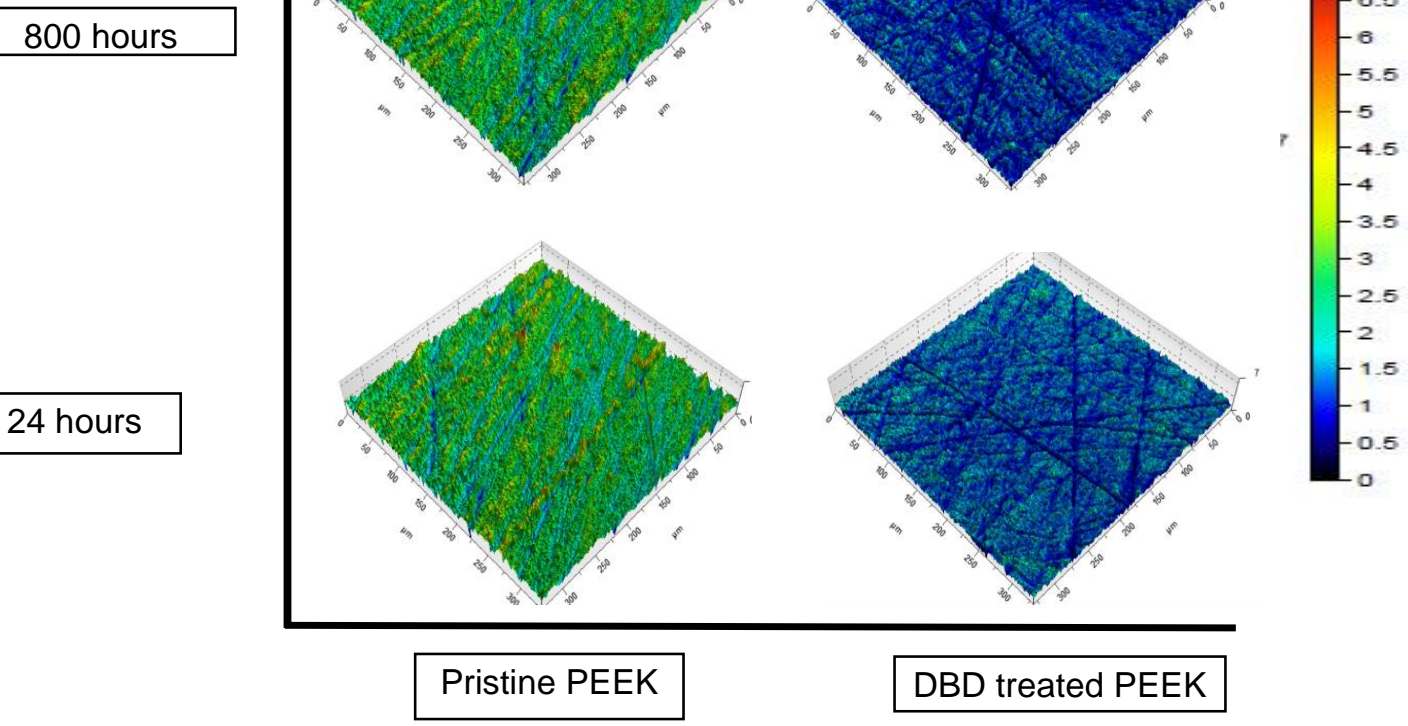

Figure 3. Non-contact profilometry of pristine and plasma-treated samples ( $330 \times 330 \mu \mathrm{m}^{2}$ surface area) for (a) PET, (b) PEEK (same scale applies to all images). 
(a)

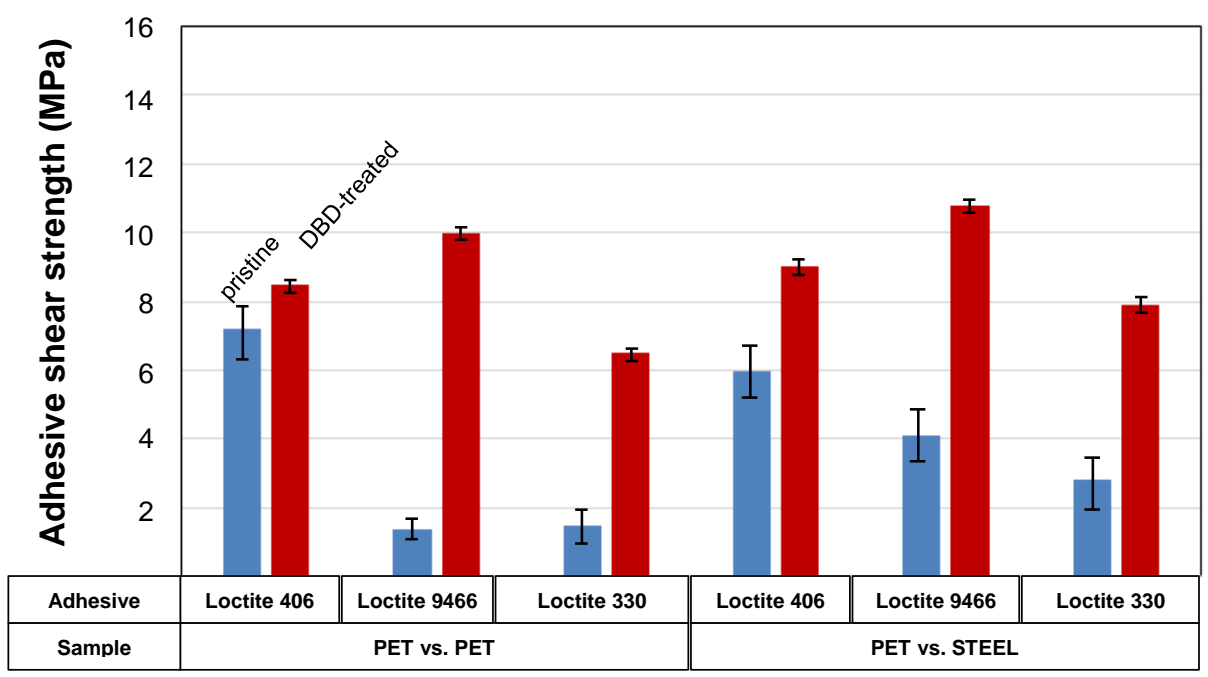

(b)

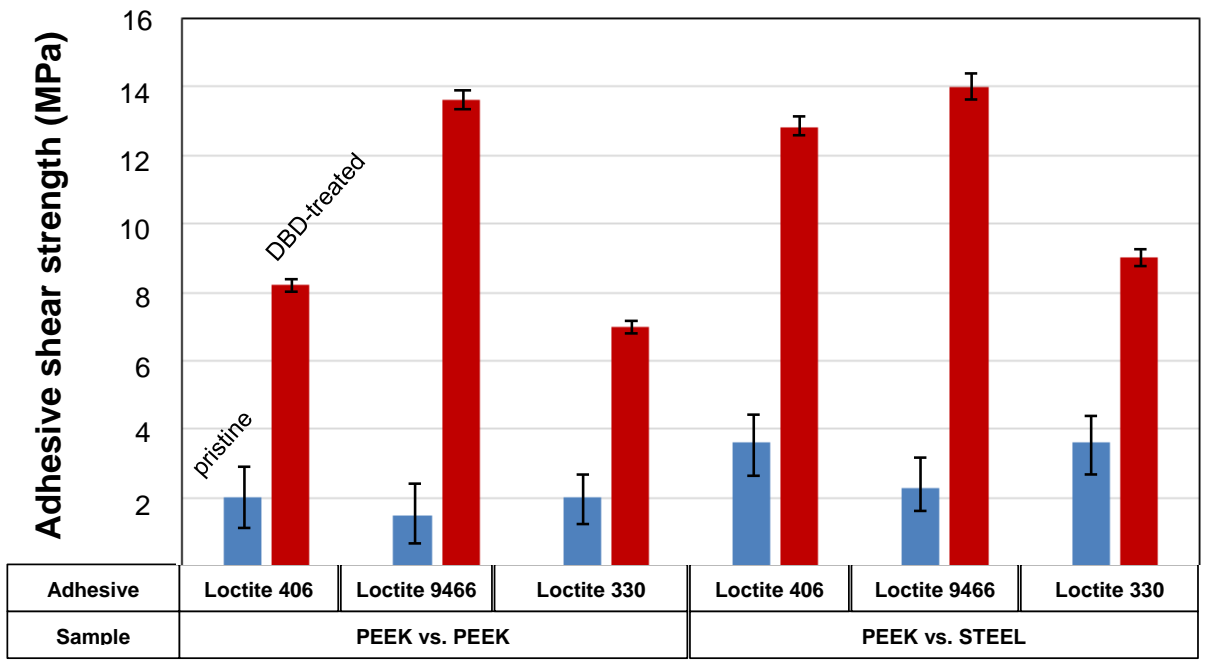

Figure 4. Adhesive testing of polymer/polymer and polymer/steel couples after application of different adhesive types for pristine samples (blue, first column) and plasma-treated samples (red, second column) for (a) PET, (b) PEEK. 
(a)

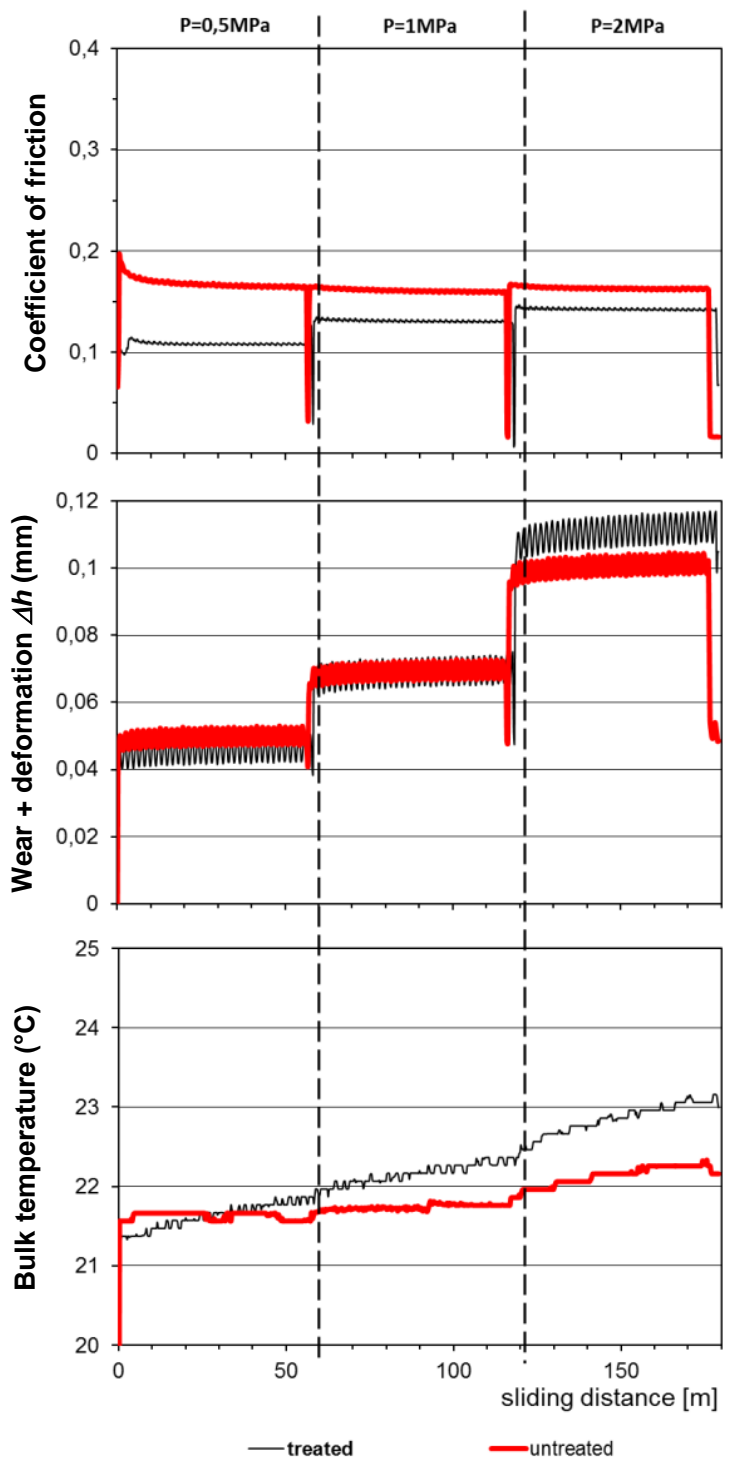

(b)

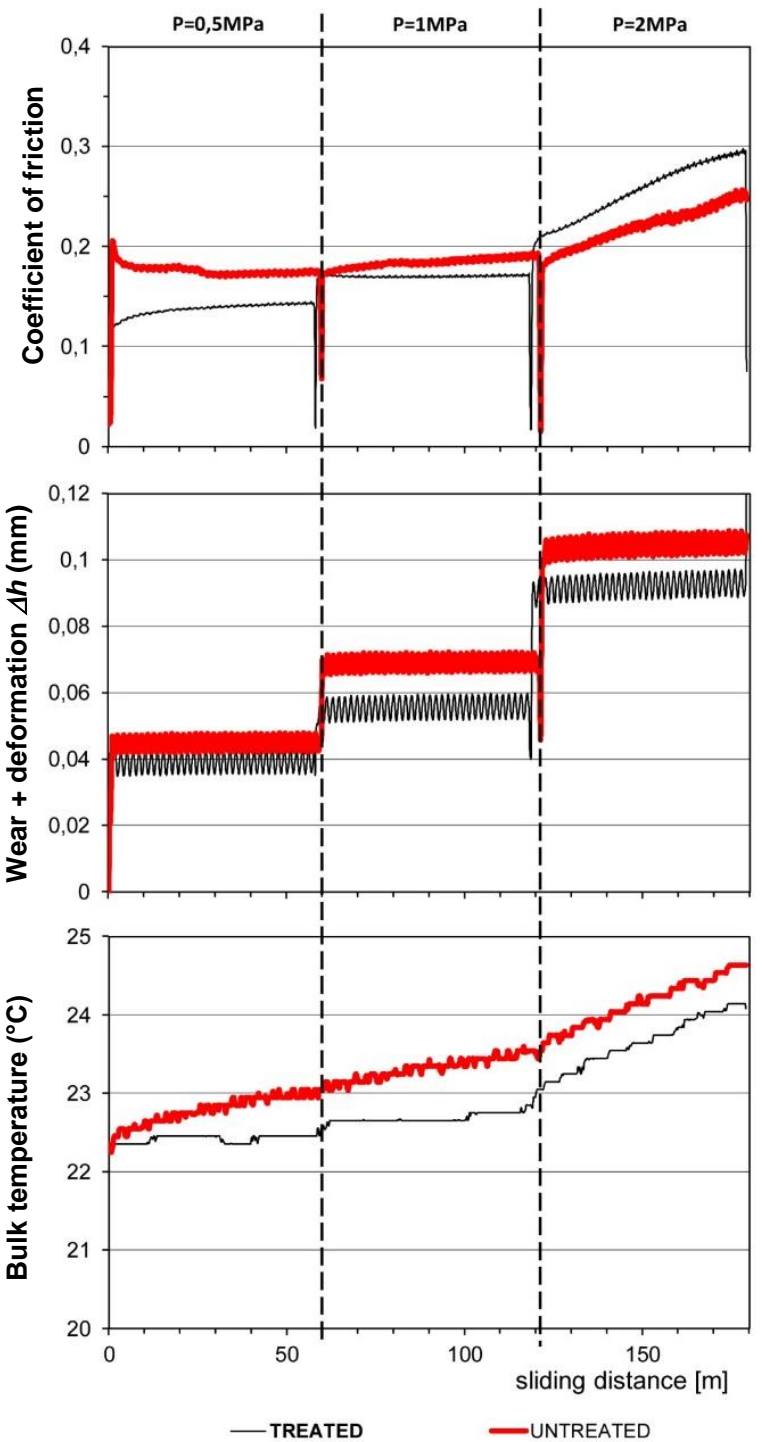

Figure 5. Tribological testing under dry sliding conditions at 0.5, 1 and $2 \mathrm{MPa}$, including on-line measurements for coefficients of friction, wear and displacement $\Delta h$, temperature for (a) PET, (b) PEEK 
(a)

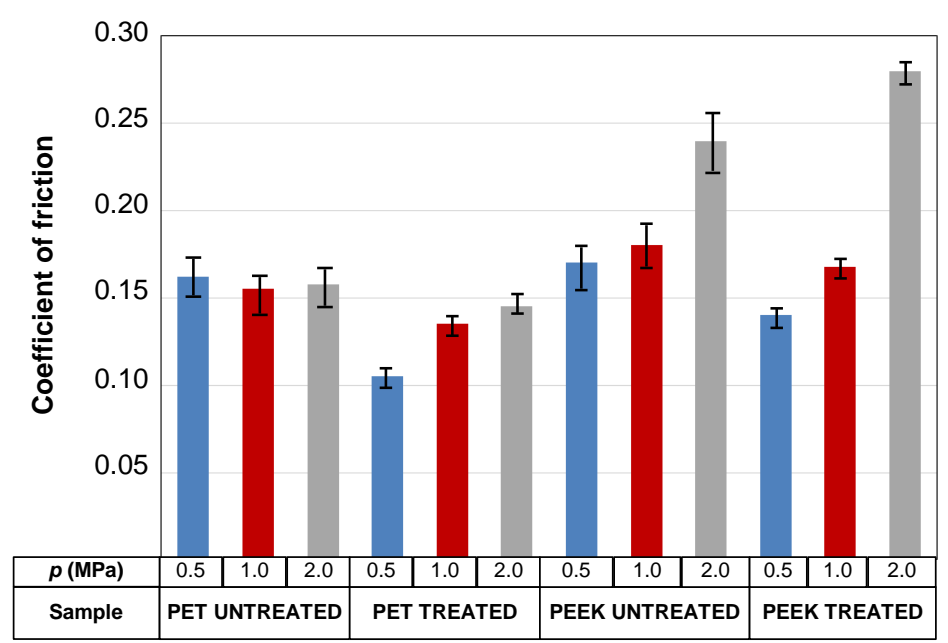

(b)

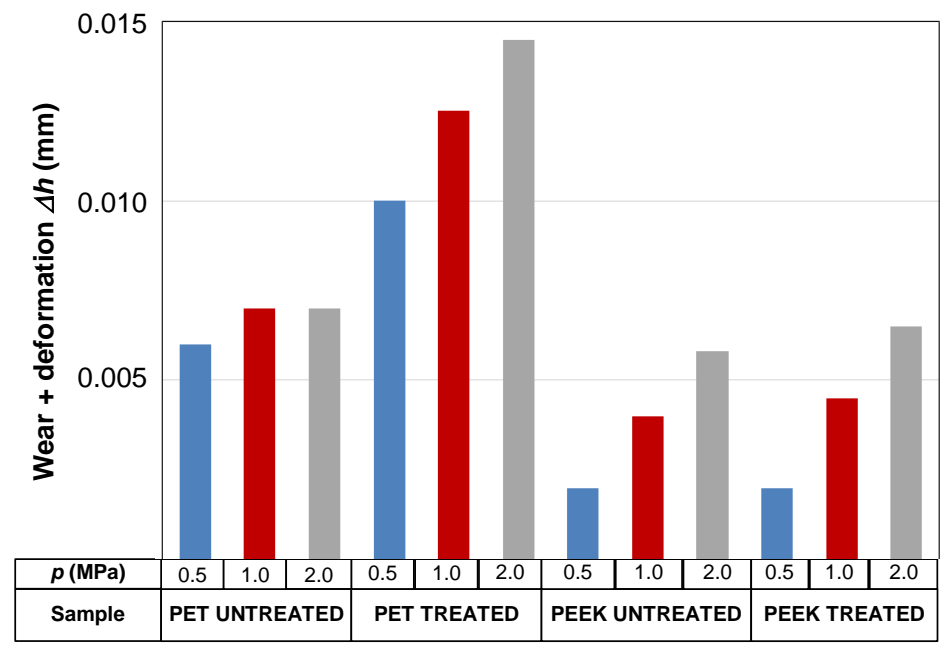

Figure 6. Tribological testing under dry sliding conditions at $0.5,1$ and $2 \mathrm{MPa}$ : summary of tribological data with (a) average coefficients of friction, (b) wear + deformation $\Delta \mathrm{h}$. 
(a)

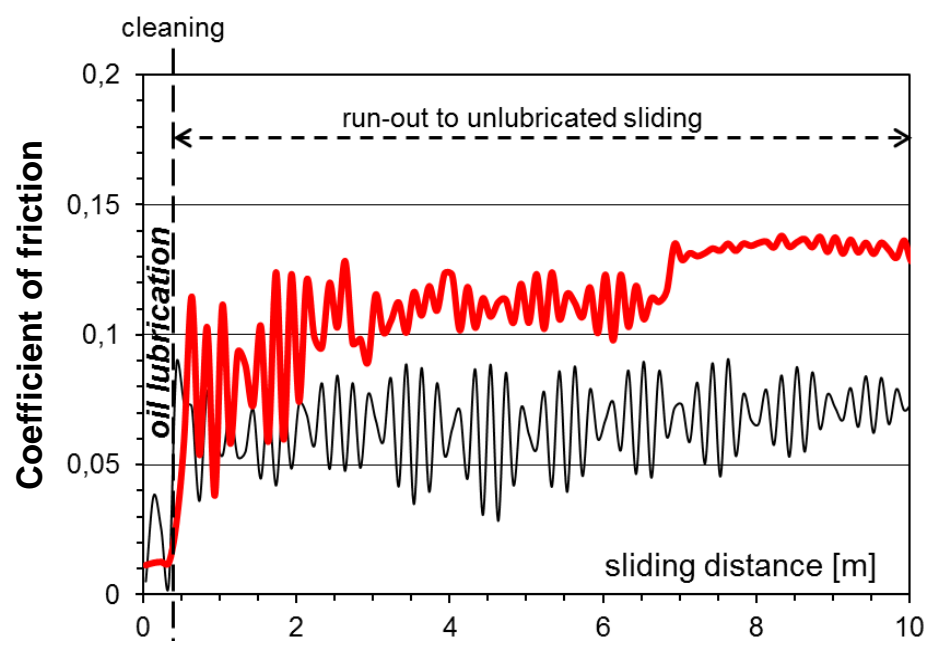

(b)

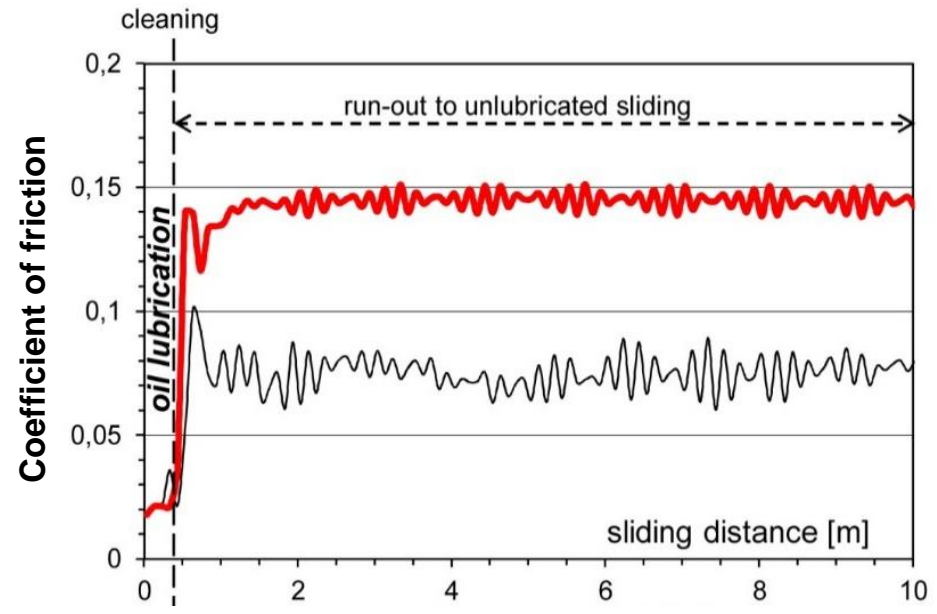

(c)

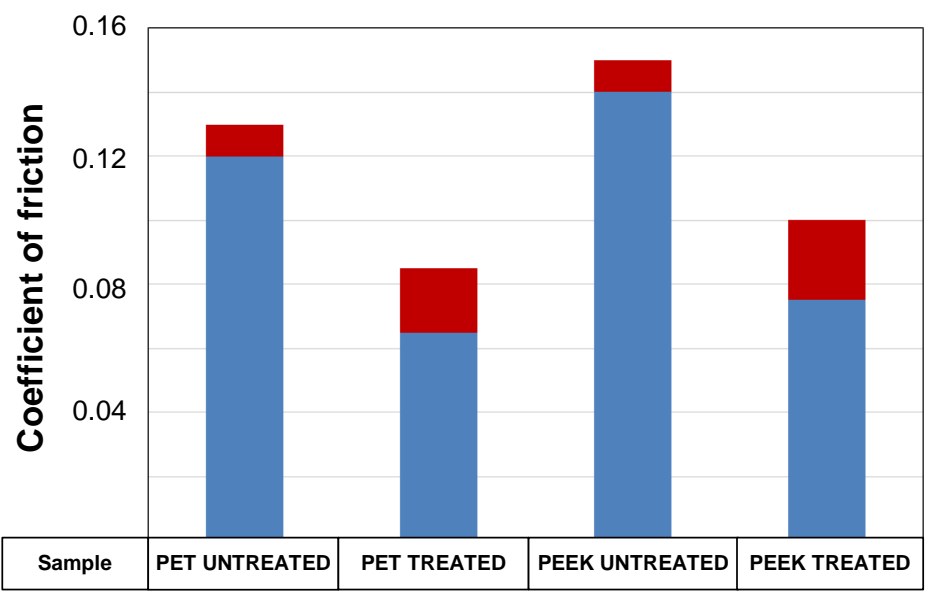

Figure 7. Tribological testing under lubricated sliding and run-out conditions at $0.5 \mathrm{MPa}$, with (a) coefficients of friction of PET, (b) coefficients of friction of PEEK, (c) summary of average and maximum coefficients of friction. 
